\title{
Oncoplastic breast reduction using the short scar periareolar inferior pedicle reduction technique
}

Yoon Soo Kim ${ }^{1}$, Byeong Seok Kim , Ho Sung Kim ${ }^{1}$, Seok Kyung In ${ }^{1}$, Hyung Suk Yi ${ }^{1}$, Hong Il Kim ${ }^{1}$, Jin Hyung Park ${ }^{1}$, Jin Hyuk Choi ${ }^{2}$, Hyo Young Kim ${ }^{1}$

Departments of ${ }^{1}$ Plastic and Reconstructive Surgery and ${ }^{2}$ Surgery, Kosin University College of Medicine, Busan, Korea

\begin{abstract}
After a partial mastectomy, large or ptotic breasts can be reconstructed using breast reduction techniques. Wise-pattern reduction is typically used to remove masses in any quadrant of the breast, but this technique leaves a large inverted T-shaped scar. Instead, the short scar periareolar inferior pedicle reduction (SPAIR) technique involves a periareolar line and does not result in a scar along the inframammary fold (IMF). A 49-year-old patient with macromastia and severely ptotic breasts was diagnosed with invasive cancer of the left breast. Her large breasts caused pain in her back, shoulders, and neck. She also expressed concern about postsurgical scarring along the IMF. In light of this concern, we chose the SPAIR technique, and we designed and performed the procedure as described by Hammond. During surgery, we removed $36 \mathrm{~g}$ of breast tumor and $380 \mathrm{~g}$ of breast parenchyma from the left breast. To establish symmetry, we also removed $410 \mathrm{~g}$ of tissue from the right breast. Postoperatively, the patient reported satisfaction regarding the reduction mammaplasty and, in particular, noted decreased back, shoulder, and neck pain. In summary, we used the SPAIR technique to achieve oncologic and aesthetic success in a patient with macromastia and a tumor located lateral to the nipple-areolar complex.
\end{abstract}

Keywords Breast conserving surgery / Mammaplasty / Pedicled flap

\section{INTRODUCTION}

Oncoplastic surgery can be performed after partial mastectomy by reshaping or rearranging the remaining glandular tissues. The frequency of such cases has recently increased. Oncoplastic surgery can be performed with either a volume replacement or a volume displacement approach, the latter of which involves breast tissue advancement, rotation, or transposition using a breast flap or breast reduction technique [1].

Received: Mar 18, 2020 Revised: Apr 17, 2020 Accepted: May 15, 2020 Correspondence: Hyo Young Kim Department of Plastic and Reconstructive Surgery, Kosin University College of Medicine, 262 Gamcheon-ro, Seo-gu, Busan 49267, Korea

Tel: +82-51-990-6131, Fax: +82-51-990-6312, E-mail: hose3290@naver.com

Copyright () 2020 The Korean Society for Aesthetic Plastic Surgery.

This is an Open Access article distributed under the terms of the Creative Commons Attribution Non-Commercial License (https://creativecommons.org/licenses/by-nc/4.0/) which permits unrestricted non-commercial use, distribution, and reproduction in any medium, provided the original work is properly cited. www.e-aaps.org
In patients with a large breast volume or ptosis, reconstruction can be performed using a breast reduction technique, typically Wise-pattern reduction [2]. However, the Wise-pattern technique leaves a large inverted T-shaped scar [3]. Instead, in the short scar periareolar inferior pedicle reduction (SPAIR) technique, an inferior pedicle of breast glandular tissue and the periareolar line are used. As this technique leaves no scar in the inframammary fold (IMF), it is advantageous over Wise-pattern reduction [4].

Herein we report positive oncologic and aesthetic results associated with the use of the SPAIR technique in a patient who underwent partial mastectomy for breast cancer located in the upper lateral region of the nipple-areolar complex (NAC).

\section{CASE REPORT}

A 49-year-old woman received abnormal findings during a health screening and visited the breast surgery department, where she was diagnosed with invasive cancer of the left breast. The patient had macromastia with shoulder and neck pain and desired breast re- 
duction after her partial mastectomy. The nipple was located $4 \mathrm{~cm}$ below the IMF; thus, the patient met the criteria for severe ptosis (Fig. 1). The patient revealed that she was concerned about having an IMF scar; therefore, we planned to use the SPAIR technique to minimize scarring following reduction [5].

The design and procedure were performed as described by Hammond [4]. We marked the jugular notch, the midline of the chest, and the IMF. A straight line was then drawn from the midpoint of the clavicle to the nipple. When extended downward to the abdominal wall, this line divided each breast into halves. The inferior pedicle was centered on the meridian of the breast and mapped to form an 8-cm wide pedicle. By moving the breast up and outward and then up and inward, the medial and lateral extent of the periareolar pattern could be distinguished. The postoperative position of the superior margin of the NAC was more than $3 \mathrm{~cm}$ above the IMF for both breasts.

The breast surgeon made an incision along the outer line established on the left breast and excised $36 \mathrm{~g}$ of tumor tissue with sentinel lymph nodes for biopsy. After the partial mastectomy, the area between the periareolar line and the adjacent concentric circle was de-epithelialized by a plastic surgeon. The breast volume was reduced by removing a C-shaped segment of tissue (total mass of excised tissue, $380 \mathrm{~g}$ ) (Fig. 2A). The pedicle tips were joined using a key staple (Fig. 2B). By applying upward traction on the pattern, the redundant skin envelope was plicated to form a rounded lower breast pole. Once the expected shape was created, the margins of plication were marked (Fig. 2C). The marked area was de-epithelialized at the pedicle, and redundant tissue located medial and lateral to the pedicle was removed (Fig. 2D). The plicated area was sutured with Vicryl 3-0 sutures. The periareolar opening was adjusted using an interlocking purse-string suture with Prolene 2-0 sutures. A subcuticular running suture was performed using Monosyn 4-0 sutures (B. Braun Medical, Barcelona, Spain) with the subcuticular technique. Contralateral breast reduction mammaplasty was completed in the same manner. In total, $410 \mathrm{~g}$ of tissue was ex- cised from the right breast.

The biopsy results showed invasive carcinoma with clear margins. After surgery, the patient received 20 radiation therapy sessions and was administered tamoxifen hormone replacement therapy. We saw the patient for follow-up at 1 and 3 months postoperatively (Fig. 3).
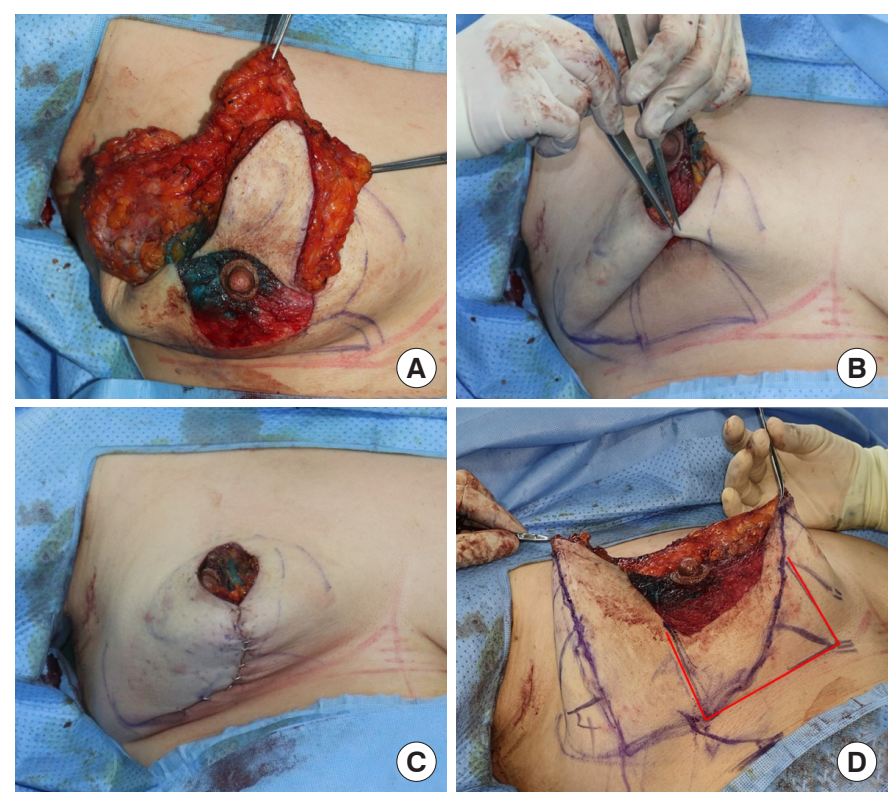

Fig. 2. Representative operative photographs. (A) Appearance of the breast after skeletonization of the pedicle. The breast was reduced by removing a $\mathrm{C}$-shaped segment of tissue from around the sides and top of the pedicle. The flaps were left sufficiently full to assist with the shaping of the breast. (B) The two points pictured were joined with a key staple. (C) The redundant skin envelope of the breast can be plicated to create a rounded lower pole. Note that the inferior end of the plication had begun to cant laterally along the inframammary fold. (D) With the staples now removed, the extent of the vertical pattern could be seen. The red line represents the inferior pedicle.
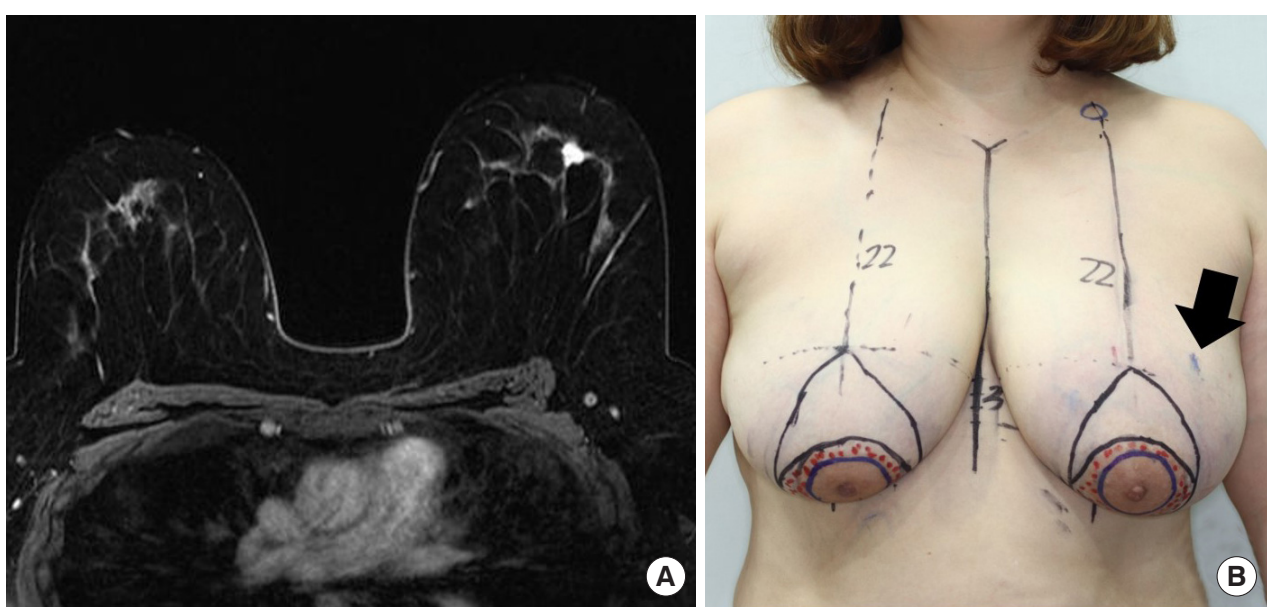

Fig. 1. Representative clinical photographs. A 49-year-old woman underwent short scar periareolar inferior pedicle reduction mammaplasty using both inferior pedicles. A total of $416 \mathrm{~g}$ was excised from the left breast and $410 \mathrm{~g}$ was excised from the right breast. (A) Preoperative high-resolution T1 post-contrast image. A mass, measuring approximately $11 \mathrm{~mm}$, is shown on the left side at the $2 o^{\prime}$ clock position. (B) Preoperative design photograph. The arrow indicates the tumor site. 


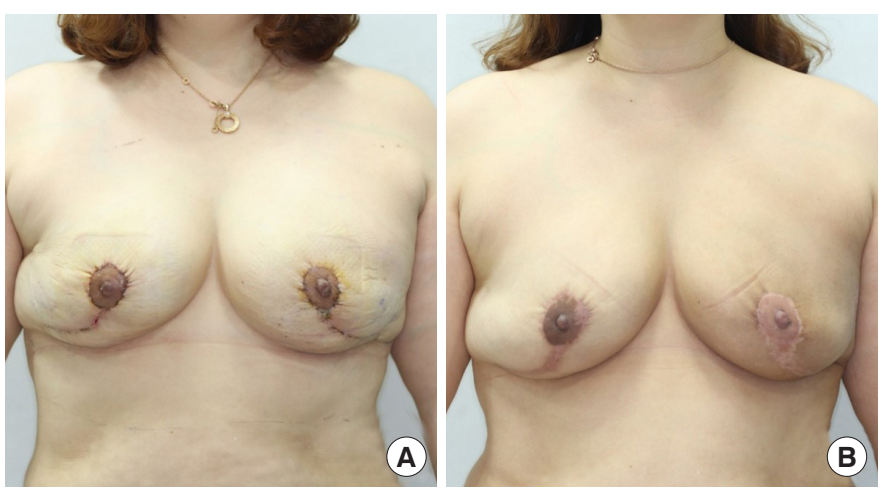

Fig. 3. Representative clinical photographs. (A) One month postoperation. The patient's breast size was reduced, and both nipple-areolar complexes were well-positioned and symmetric, as planned. (B) Three months postoperation. A widened immature scar can be observed in the periareolar and inferior breast areas.

\section{DISCUSSION}

We achieved successful surgical outcomes using the SPAIR technique in a patient with invasive ductal cancer that measured $1.2 \times 0.9$ $\mathrm{cm}$ and was located in the upper outer quadrant. The patient's oncologic and aesthetic results were satisfactory.

Oncoplasty, which has been used since the mid-1990s, refers to the reshaping of breast tissue after a partial mastectomy. Oncoplasty enables the resection of large tumors by combining extirpative surgery with breast reduction surgery. Breast reduction techniques can be used to avoid unsatisfactory aesthetic outcomes after partial mastectomy [4]. Oncoplasty also has oncologic advantages, since the removal of a large volume of glandular tissue helps ensure adequate tumor resection margins [6].

The rate of occult breast cancer in contralateral symmetrizing reduction specimens obtained from patients who underwent breast reconstruction ranges from $4.6 \%$ to $11 \%$ [6]. In breast-conserving therapy (BCT) involving standard lumpectomy alone, cosmesis is affected by breast size. Women with either very small or very large breasts tend to experience relatively poor outcomes. Macromastia has been estimated to be present in up to $40 \%$ of women treated with BCT [7], with a lower estimated rate among Asian women. Since most patients with breast cancer are over 50 years of age, oncoplastic reduction is expected to be indicated in a large number of cases. In patients with macromastia, the aesthetic outcomes of lumpectomy alone might not be ideal. In women with large breasts, BCT may leave an empty sac that can result in a ptotic breast. This can lead to heterogeneous tissue distribution resulting from repeated positioning over an extended course of treatment [8]. Oncoplastic breast reduction helps avoid these complications-particularly those related to larger breasts-while satisfying the initial goal of cancer treatment [9]. In our case, radical resection of the glandular tissue allowed for a sufficient safety margin. The patient was also pleased to experience pain relief in her shoulders, neck, and back after surgery.

Oncoplastic reduction of this nature is usually performed through a Wise-pattern reduction. Based on the tumor location, techniques such as vertical scar mammaplasty, omega plasty, and lateral mammaplasty can also be used $[1,10,11]$. We did not choose to utilize a Wise-pattern reduction, as it is associated with a large inverted Tshaped scar. Vertical scar mammaplasty is suitable when the reduction volume is not large and when the tumor is located inferior to the NAC, since this technique involves the use of a superior pedicle.

The SPAIR technique, originally proposed by Hammond, allows a reduction of as much as $800 \mathrm{~g}$ per side. An additional advantage of the SPAIR technique is that it does not scar the IMF $[4,12]$. The superior and medial regions of the NAC are left with thick tissue, while all glandular tissue in the lateral region is removed. This leaves the lateral side with only a thin skin flap. This method was well-suited to our case, since the tumor was located on the lateral side of the NAC. When a tumor is located superior or medial to the NAC and near the skin, the postoperative volume may appear insufficient in the superior or medial region due to the thinness of the skin flap. In such cases, prior to surgery, patients should be counseled to expect a suboptimal appearance relative to cases in which the tumor is located lateral to the NAC. Tumor excision margins must also be discussed thoroughly with the breast surgeon. Since the SPAIR technique widely removes glandular tissue, it can be used regardless of tumor size, except when the tumor is located inferior to the NAC. More studies are needed regarding surgical technique selection relative to tumor location.

After breast-conserving surgery, we performed an oncoplastic SPAIR technique, considering the following facets of our case. To establish breast symmetry, the weight of the tumor was added to the weight of reduction of the left breast. The breast surgeon removed $36 \mathrm{~g}$ of the breast, and an additional $380 \mathrm{~g}$ was removed as part of breast reduction. Therefore, we removed $410 \mathrm{~g}$ of tissue from the contralateral breast, and symmetry was confirmed with the patient in a sitting position. When dissecting the lateral region of the contralateral breast, the thickness of the skin should be similar to that of the skin flap above the excised tumor.

Three months after surgery, an immature widened scar was observed in clinical photographs (Fig. 3B). Mild tension occurred during skin closure because the amount of skin excision was excessive relative to the amount of glandular tissue removed. Tension in the skin flap can cause problems related to scar formation and pedicle circulation. To avoid excessive skin excision, surgeons should avoid making the vertical lines on the right and left sides too far apart. The skin excision does not need to be extensive, as subcutaneous dissection allows for the wide excision of glandular tissue. It is also important to leave a thin lateral skin flap in order to achieve tension-free closure.

One limitation of this case report is the short-term nature of the 
follow-up period. More SPAIR cases and longer-term follow-up periods are needed to evaluate oncologic outcomes, such as the 5-year survival rate, and aesthetic results.

Hammond et al. [13] reported that GORE-TEX sutures (W.L. Gore \& Associates) were advantageous for controlling the areolar diameter. However, due to import limitations, we instead used Prolene 2-0 sutures and achieved comparable results.

In conclusion, we applied the SPAIR technique for oncoplastic reduction and achieved successful oncologic and aesthetic outcomes in a patient with macromastia and a tumor located lateral to the NAC.

\section{NOTES}

\section{Conflict of interest}

No potential conflict of interest relevant to this article was reported.

\section{Ethical approval}

The study was performed in accordance with the principles of the Declaration of Helsinki.

\section{Patient consent}

The patient provided written informed consent for the publication and the use of her images.

\section{ORCID}

Yoon Soo Kim

Byeong Seok Kim

Ho Sung Kim

Seok Kyung In

Hyung Suk Yi

Hong Il Kim

Jin Hyung Park

Jin Hyuk Choi

Hyo Young Kim https://orcid.org/0000-0002-8073-5511

https://orcid.org/0000-0003-1375-1092

https://orcid.org/0000-0002-6030-3199

https://orcid.org/0000-0003-4346-7949

https://orcid.org/0000-0002-9584-8201

https://orcid.org/0000-0002-5505-9945

https://orcid.org/0000-0001-9415-2467

https://orcid.org/0000-0001-5625-0912

https://orcid.org/0000-0002-1834-5766

\section{REFERENCES}

1. Anderson BO, Masetti R, Silverstein MJ. Oncoplastic approaches to partial mastectomy: an overview of volume-displacement techniques. Lancet Oncol 2005;6:145-57.

2. Crown A, Handy N, Rocha FG, et al. Oncoplastic reduction mammaplasty, an effective and safe method of breast conservation. Am J Surg 2018;215:910-5.

3. Kronowitz SJ, Kuerer HM, Buchholz TA, et al. A management algorithm and practical oncoplastic surgical techniques for repairing partial mastectomy defects. Plast Reconstr Surg 2008;122:1631-47.

4. Hammond DC. The SPAIR mammaplasty. Clin Plast Surg 2002;29: 411-21.

5. Frank L, Ryan EA, Jamil A. Reduction mammoplasty with short scar techniques. In: Neligan P, editor. Plastic surgery. 4th ed. London: Elsevier Saunders; 2017. p. 160-73.

6. Giacalone PL, Roger P, Dubon O, et al. Comparative study of the accuracy of breast resection in oncoplastic surgery and quadrantectomy in breast cancer. Ann Surg Oncol 2007;14:605-14.

7. Petit JY, Rietjens M, Contesso G, et al. Contralateral mastoplasty for breast reconstruction: a good opportunity for glandular exploration and occult carcinomas diagnosis. Ann Surg Oncol 1997;4:511-5.

8. Dundas KL, Atyeo J, Cox J. What is a large breast? Measuring and categorizing breast size for tangential breast radiation therapy. Australas Radiol 2007;51:589-93.

9. Taylor ME, Perez CA, Halverson KJ, et al. Factors influencing cosmetic results after conservation therapy for breast cancer. Int J Radiat Oncol Biol Phys 1995;31:753-64.

10. Chang MM, Huston T, Ascherman J, et al. Oncoplastic breast reduction: maximizing aesthetics and surgical margins. Int J Surg Oncol 2012;2012:907576.

11. Hernanz F, Regano S, Vega A, et al. Reduction mammaplasty: an advantageous option for breast conserving surgery in large-breasted patients. Surg Oncol 2010;19:e95-102.

12. Hammond DC. The short scar periareolar inferior pedicle reduction (SPAIR) mammaplasty. Semin Plast Surg 2004;18:231-43.

13. Hammond DC, Khuthaila DK, Kim J. The interlocking Gore-Tex suture for control of areolar diameter and shape. Plast Reconstr Surg 2007;119:804-9. 